\title{
Forest observational studies-an essential infrastructure for sustainable use of natural resources
}

\author{
XiuHai Zhao ${ }^{1}$, Javier Corral-Rivas ${ }^{2}$, ChunYu Zhang ${ }^{1}$, Hailemariam Temesgen ${ }^{3}$ and Klaus v Gadow ${ }^{4,5^{*}}$
}

\begin{abstract}
This contribution complements Forest Ecosystems' Thematic Series on "Forest Observational Studies". We provide essential clarification regarding the definition and purpose of long-term field studies, review some of the extensive literature and discuss different approaches to collecting field data. We also describe two newly established forest observational networks that serve to illustrate the scope and diversity of forest field studies. The first is a large-scale network of forest observational studies in prominent natural forest ecosystems in China. The second example demonstrates observational studies in mixed and uneven-aged pine-oak forests which are selectively managed by local communities in Mexico. We summarize the potential for analysing and modeling forest ecosystems within interdisciplinary projects and provide argumentation in favour of long-term institutional commitment to maintaining forest observational field studies.
\end{abstract}

Keywords: Mexico; China; India; Longitudinal; Cross-sectional; Interval study; Experiment; Social media surveillance

\section{Review}

This section clarifies definitions and reviews some of the extensive literature relating to forest resource assessments, manipulated experiments and observational studies in forest ecosystems. Some parts were previously presented in two workshop proceedings that had not been subject to peer review (Zhao et al. 2011, 2012; Amateis and Burkhar 2012).

\section{Forest resource assessments (forest inventories)}

The objective of a resource assessment, such as a National Forest Inventory (NFI), is to provide unbiased estimates of particular target variables and to present statistics about forest resources. NFIs assess forest areas, growing stock volumes, and changes in biodiversity status, landuse, carbon stock and ecosystem services. International agreements, including the Montréal Process (1998), the Ministerial Conference on the Protection of Forests in Europe (2008) and the Convention on Biological Diversity

\footnotetext{
* Correspondence: kgadow@gwdg.de

${ }^{4}$ Burckhardt Institute, Georg-August University, Göttingen, Germany

${ }^{5}$ Institute of Forestry and Wood Science, University of Stellenbosch, Stellenbosch, South Africa

Full list of author information is available at the end of the article
}

(2008), require information which is provided by NFIs. In North America, the Forest Inventory and Analysis (FIA) Program of the U.S. Forest Service provides the information needed to assess America's forests (LaBau et al. 2007). Naturally, sampling designs, sample plot configurations and other assessment methods may vary among countries and there is diversity in the definitions of forest area and growing stock volume among countries. Thus, harmonizing assessment and reporting is essential to make NFI results comparable (Tomppo et al. 2010).

\section{Manipulated experiments}

A manipulated experiment is an investigation that attempts to establish a particular set of conditions under a specified protocol with the aim of testing a hypothesis. The adjective manipulated implies the establishment of a set of predefined treatments which allow comparison of the effects/ responses resulting from these treatments (Fisher 1935; Cox 1958; Gadow and Kleinn 2005). Thus, the experiment deliberately imposes a treatment on a group of objects in the interest of observing the response. Examples of manipulated experiments include medium and long-term growth studies in response to different fertilizer applications and stand densities (O'Hehir 2001; Burkhart and 
Tomé 2012), growth studies of clones on different sites, including marginal ones (Bungart and Hüttl 2004), growth and competition effects in multi-species forests (Vanclay 1994; Pretzsch 2009), or evaluating effects of afforestation on water yield in mountain catchments (Bosch and Gadow 1990). Despite attempts to create homogenous conditions, manipulated field experiments always involve uncertainties in controlling ceteris paribus conditions, which are necessary for obtaining noise-free "dose/response" relations.

Manipulated field experiments do not seem to be as popular as they used to be during the 1960's and 70's. Possible reasons are the high cost of maintaining the field experiments and the restricted ability to generalize beyond the homogeneous, and therefore limited, experimental conditions. An exception is the impressive network of the Forest Modeling Research Cooperative at Virginia Tech which has employed a combination of permanent sample plots in operational stands of loblolly pine (Pinus taeda) plantations and designed experiments to provide data bases needed to construct robust growth and yield models for projecting inventories and estimating response to a wide range of silvicultural treatments for plantations established primarily for wood production (Burkhart 2008). These extensive networks have provided the empirical base for models of tree taper and volume, site index, and tree and stand increment and mortality. Data from spacing trials that were measured annually over a 25-year period (Amateis and Burkhart 2012) and from silvicultural trials designed for estimating response to control of competing vegetation and fertilizer applications extend and enhance the basic modeling framework. (Amateis and Burkhar 2012). Because the plots were stem-mapped and measured regularly, it was possible to obtain data on decay rates and amounts of carbon in the dead trees at the time plot measurements were scheduled to be terminated in the first region-wide study (Radtke et al. 2009). With increased interest in climate influences on forests, both region-wide data sets, which cover a broad range of soil and climate zones where loblolly pine is planted, are providing highly valuable data for a large multi-disciplinary, multi-institutional research effort aimed at assessing climate influences on southern U.S. conifers (http://www.pinemap.org).

\section{Forest observational studies}

Models of forest ecosystem dynamics, including tree growth, mortality and recruitment, are often developed on the basis of repeated observations in specially selected observational field plots. Selection of sites is not random or systematic, as in forest inventories, but based on particular data requirements. Ecologists tend to use the term "opportunistic sampling" for this approach (De Barba et al. 2010). The aim of the early field experiments established during the $19^{\text {th }}$ century was to measure the growth of trees which were numbered for re-identification during successive measurements. Some of these experiments have been maintained for over a century, providing valuable information on long-term developments (Spellmann et al. 1996). The field plots are usually larger than inventory plots, and measurements are often much more detailed. Despite advances in resource assessment technology, there seems to be a real need for long-term observational field studies with mapped trees in large field plots. Examples of the design and implementation of such studies are presented by Zhao et al. (2011), Corral-Rivas et al. (2012), Tewari et al. (2014) and Kiviste et al. (2012).

In contrast to a manipulated experiment, which deliberately imposes treatments on experimental plots with the aim of observing a particular response, a comparative observational study involves collecting and analysing data from different site conditions without actively pre-defining these conditions (Kuehl 1994). Comparative observational studies are also known as quasi-experiments (Campbell and Stanley 1963; Cook and Campbell 1979). Typical quasi-experiments are longterm forest observational studies. Extensive networks of longterm forest observational studies have been established since the middle of the nineteenth century. Franz v. Baur (1830-1897), Bernhard Danckelmann (1831-1901) and Gustav Heyer (1826-1883) were among the first who devised a concept for long-term investigations in forest science, emphasising the importance of experimental field plots. In 1929 the International Union of Forest Research Organisations (IUFRO) was established with the objective of standardising the design and analysis of long-term field experiments (Pretzsch 2009). The majority of these experiments are observational studies (Szaro et al. 2006). Numerous observational studies were also established in North America. (Seymour et al. 2006a) reviewed long-term silvicultural experiments in four regions of the United States. As early as the 1920s, when there was much interest in multi-aged silviculture, scientists recognized that silvicultural systems involving within-stand variation of tree age and size could not be tested effectively on small ( $<1 \mathrm{ha})$ plots, and began installing compartmentscale (10-20 ha) trials on many experimental forests throughout the United States. Such large-scale trials have experienced a revival during the 1990's in response to a renewed interest in management methods aiming to maintain within-stand structural complexity and biodiversity at larger scales.

\section{Longitudinal, cross-sectional and interval studies}

Forest ecosystem studies are often designed as longterm experiments, which are known in the statistical literature as longitudinal studies. The key feature of longitudinal data is the fact that the same individual is repeatedly measured at successive points in time. Thus, the set of observations on one individual subject will tend to be positively correlated and this correlation needs to be taken 
into account (Crawley 2005, p. 180). Longitudinal studies are commonly used to describe and explain trends. One disadvantage of a longterm or "permanent" experiment is the high maintenance cost of the research infrastructure and the long wait for results (Zhao et al. 2011).

On the other hand, results are available relatively quickly in a cross-sectional study (also known as a chronosequence) which involves one-time measurements of a set of field plots which usually cover a wide range of ages and environmental conditions. Thus, the sequence of remeasurements in time (longitudinal study) is substituted by simultaneous measurements in space. This method has been used extensively during the $19^{\text {th }}$ century (Kramer 1988, p. 97). Cross-sectional studies may be combined with stem analyses to reconstruct the development of tree height, for example (Lee 1993). They may provide information relatively quickly, but do not capture the response of a target variable to a given initial state. The initial state may be defined for example, by the competition effects in the past. A cross-sectional study evaluates differences in growth in response to different site conditions. It does not provide evidence that can be used to test an effect such as past forest density or competition. A cross-sectional study is the only possible approach, however, in experiments requiring destructive sampling, i.e. in biomass studies where individual trees, or a cohort of trees within a given area, have to be cut up, dried and weighed. Obviously, the selection of the particular individuals or the particular cohorts will greatly influence the results. A cross-sectional study provides one-time measurements for many individuals, but no rates of change. A longitudinal study does assess rates of change, but usually only for few individuals. Thus, there are two extreme cases (Crawley 2005, p. 180):

1. few measurements on many individuals

2. many measurements on few individuals

Cross-sectional studies typically involve few observations on a large number of individuals while in longitudinal studies few individuals are typically measured many times. A practical compromise between a longitudinal study and a cross-sectional study is an interval study. Interval plots are measured at least twice with the objective of assessing the rate of change of a target variable between successive re-measurements. As many sites as possible should be covered and there is no immediate need to observe the target variable for long periods of time. Thus interval studies strike a compromise, exploiting the primary advantages of longitudinal experiments (gathering specific age and cohort-related responses) and cross-sectional studies (broad coverage of site conditions and minimum wait for data). However, continuous observations over long time periods are indispensable for assessing certain longterm effects, such as maximum density and tree survival for different ages and initial espacements, and the effects of changing environmental conditions.

An important question concerns the balance between the number of growth intervals that should be assessed in one particular location and the range of environmental and treatment conditions that needs to be covered. In the ideal case, one growth interval will provide sufficient response and the funds that would be required for assessing a second interval at the particular location can be spent on gathering another set of interval data in a different locality. An interval plot should be continued after one growth period if new results are expected, or it may be abandoned and the available funds used in another location to increase the variety of initial states for which the response needs to be evaluated. Generally, interval plots are continued for multiple growth periods, but ongoing evaluation should be carried out of the tradeoff between abandoning current interval plot locations and establishing new plots in additional locations to increase the variety of initial states for which response data are needed.

Some plots have been continuously re-measured over long periods of time. Pelz and Kohnle (2012) list numerous examples of long-term field studies in Germany. New networks of such studies, some rather extensive, were established more recently. The impressive examples from the US, China and Mexico are described below in more detail. However, there are also examples of observational studies that had been established during the early years of the 20th century, were subsequently abandoned (usually after political change caused by a revolution or independence) and are being re-initiated. One such series was described by Sims et al. (2009). Concerted efforts are also being made in India to locate and revive old plots which had been established during colonial times (Tewari et al. 2014).

The ultimate aim of all field studies is to provide external validity, the ability to generalize from a limited set of observations. Generalizability depends on whether the observed response measurement is representative of a population of interest. Scientists need to clarify whether the results of the observations may be legitimately extended to the general population of interest. In theory, it should be possible to extend observations beyond the particular restricted data set. However, this is not always possible in practice, for example in the case of rare biotopes or endangered species that occur in geographically restricted areas. A comprehensive description of the study sites and of the methodology is helpful for users to judge whether the results are applicable to a particular situation.

\section{Resource assessments, manipulated experiments and observational studies}

Thus, according to Zhao et al. (2011) we may distinguish three common approaches for collecting field data in 
forest ecosystems: Resource Assessments, Field Experiments and Observational Studies. Resource Assessments are usually carried out at regular intervals, providing geographical information about specific target variables (biomass; tree species). The data are used for formulating policy by governments, land managing agencies and NGOs, for forest planning, and for locating timber resources and new processing facilities. A manipulated experiment deliberately imposes treatments on experimental plots with the aim of observing a particular response. Field experiments are more often designed for planted forests with the aim of developing optimum silvicultural treatments. Observational studies are often laid out in natural forests with irregular structures where treatments are difficult to define. Data are collected from different site conditions without actively pre-defining these conditions. Field plots are usually large to capture effects of scale, and assessments are scheduled to coincide with a disturbance. Resource Assessments, Field Experiments and Observational Studies may complement each other. However, in Observational Studies the primary objective is not hypothesis testing or geographical coverage, but improved understanding of ecosystem dynamics, especially regarding the immediate and long-term effects of harvest events and other disturbances.

Numerous long-term observational studies with small, large and nested plot structures have been installed and maintained by various institutions in different countries covering different time periods and diverse forest ecosystems. The utility of each design depends on specific data requirements (forest trees, or other vegetative life forms) and available funds. The following two examples represent successful new implementations.

\section{Examples}

This section briefly presents details of the development and current status of two large observational networks, the Beijing observational network in China and the Durango observational network in Mexico. The two studies provide information about forest dynamics in multi-species, uneven-aged forests which are unmanaged (China) and multi-species, uneven-aged forests which are subject to selective harvesting (Mexico). As such, these studies are representative of unmanaged and managed (near-) natural ecosystems.

\section{The Beijing forest observational network}

The first three field plots of the Beijing Forest Ecosystems Observation Network were established in 2005 in the Changbaishan forest region (plots $3 \mathrm{a}, 3 \mathrm{~b}$ and $3 \mathrm{e}$ in Table 1). Two of these plots had been selectively cut by the Forestry Bureau in 1998. The third plot had been left unmanaged. Establishing managed and unmanaged field plots in close vicinity to each other has since become one of the guiding principles of the network. Standard methods of assessment were also defined at that time. During the past decade, the network has expanded to include all of the most important natural forest ecosystems in China (Figure 1).

Some details of the field plots and plot clusters are presented in Table 1. The network includes managed and unmanaged experiments. Both are designed to study ecosystem structure and dynamics, including tree growth, recruitment and mortality. The focus in the unmanaged series is on a wide range of topics that are of interest to ecologists, such as species-habitat associations; genderrelated biomass partitioning; natural ecosystem structure and diversity; response to natural disturbances such as wildfire; seed dispersion and seedling survival.

The development in the managed experiments is characterized by regular human disturbance through selective harvesting. Thus, the major objectives in the managed series is to assess and analyse modifications of ecosystem structure and diversity caused by harvest events, to study forest dynamics under management and to develop practical guidelines for selective harvesting under continuous cover forestry. Assessments are not limited to measuring trees. Flowers and fruits of dioecious tree and shrub species are collected, tree ring data assessed, seeds and seedling survivals counted, biomass components sampled and the response of the leaf spectral reflectance to above- and belowground competition is studied under field conditions.

Intensive research started immediately after the plot installations and first results were published after suitable datasets became available (Zhang et al. 2009a; Zhang et al. 2009b; Gao et al. 2010; Zhang et al. 2010a; Zhang et al. 2010b; Liu et al. 2011; Wang et al. 2011). The future objectives of the network include the need to secure long term institutional support, the desire to attract scholars from a variety of disciplines, a focus on harvest event analysis and continuing research on ecosystem structure and change.

Maintenance and extension of the new forest observational network is currently secured for periods up to 5 years in accordance with the five-year plans of the People's Republic of China (Chinese: 中国五年计划; Pinyin: Zhōngguó Wǔnián Jihuà) and its economic development guidelines. Additional support is secured from time to time by shortterm projects extending over periods of $1-2$ years. Because of the enormous size of the network and the country-wide coverage of virtually all the important forest ecosystems, the network requires institutional support to ensure the survival of this unique "Green Infrastructure", and the establishment of several observational headquarters in different parts of the country is currently being discussed.

\section{The Durango forest observational network}

The forest ecosystems of Durango, covering approximately 5 million hectares, represent the most important timber 
Table 1 Some details of the field research clusters

\begin{tabular}{|c|c|c|c|c|c|c|c|c|}
\hline No. & English name & Chinese name & Type & Near & Area (ha) & Forest type & 1st meas & 2nd meas \\
\hline 1 & Liangshui & 凉水 & $U$ & NA & 30.0 & Md & 2010 & - \\
\hline $2 a$ & Jiaohe UN & 蛟河UN & U & V & 10.0 & Md & 2010 & - \\
\hline $2 b$ & Jiaohe UF & 蛟河UF & $u$ & $\mathrm{NE}$ & 20.0 & Md & 2010 & - \\
\hline $2 c$ & Jiaohe UN & 蛟河UN & U & $\mathrm{F}$ & 21.1 & Md & 2010 & - \\
\hline $2 d$ & Jiaohe CRN & 蛟河CRN & $C R$ & V & 10.0 & Md & 2010 & - \\
\hline $2 e$ & Jiaohe CRF & 蛟河CRF & $C R$ & $\mathrm{NE}$ & 20.0 & Md & 2010 & - \\
\hline $2 f$ & Jiaohe UN & 蛟河UN & $C R$ & $\mathrm{~F}$ & 21.1 & Md & 2009 & - \\
\hline $2 \mathrm{~g}$ & Jiaohe UA & 蛟河UA & $u$ & NA & 30.0 & Md & 2010 & - \\
\hline 3a & Changbaishan I CMNa & 长白山I CMNa & CM & V & 5.2 & Md & 2005 & 2010 \\
\hline $3 b$ & Changbaishan I CMNb & 长白山I CMNb & CM & $\mathrm{F}$ & 5.2 & Md & 2005 & 2010 \\
\hline $3 c$ & Changbaishan I UF & 长白山I UF & U & NA & 5.2 & Md & 2007 & - \\
\hline $3 d$ & Changbaishan I UNa & 长白山I UNa & $u$ & NE & 1.4 & Md & 2006 & - \\
\hline $3 e$ & Changbaishan I UNb & 长白山I UNb & $u$ & NA & 1.0 & Md & 2005 & 2010 \\
\hline $4 a$ & Changbaishan II UV & 长白山II UV & $u$ & NA & 5.2 & $\operatorname{Pin} / A b$ & 2008 & - \\
\hline 6 & Keqi & 克旗 & $u$ & NA & 4.0 & Pinus & 2008 & - \\
\hline 7 & Songshan & 松山 & $u$ & NA & 1.2 & Pinus & 2007 & - \\
\hline 8 & Heilihe & 黑里河 & $u$ & NA & 4.0 & Pinus & 2007 & - \\
\hline 9 & Taiyueshan & 太岳山 & U & $? ?$ & 4.0 & Pinus & 2007 & - \\
\hline 10 & Helanshan & 贺兰山 & U & NA & 10.0 & Pinus & planned & - \\
\hline 11 & Wanglang & 王朗 & U & NA & 10.0 & $\mathrm{Pic} / \mathrm{Ab}$ & planned & - \\
\hline 12 & Jiuzhaigou & 九寨沟 & $u$ & NA & 4.0 & $\mathrm{Pic} / \mathrm{Ab}$ & 2007 & - \\
\hline 13 & Jiuzhaigou & 九寨沟 & $u$ & NA & 4.0 & Pinus & 2007 & - \\
\hline 14 & Laojunshan & 老君山 & U & NA & 4.0 & $P i c / A b$ & 2008 & - \\
\hline 15 & Yulongxueshan & 玉龙雪山 & U & NA & 4.0 & $P i c / A b$ & 2008 & - \\
\hline 16 & Linzhi & 林芝 & U & NA & 4.0 & $\mathrm{Pic} / \mathrm{Ab}$ & planned & - \\
\hline 17 & Qilianshan & 祁连山 & $u$ & NA & 10.0 & Pinus & 2010 & - \\
\hline 18 & Tianshan & 天山 & U & NA & 4.0 & Picea & 2007 & - \\
\hline 19 & Jiulianshan & 九连山 & U & NA & 5.0 & $B E$ & 2009 & - \\
\hline
\end{tabular}

$\mathrm{V}, \mathrm{F}, \mathrm{NE}$ and NA refer to the assumed "nearness" to a natural state $(\mathrm{V}=$ very far; $\mathrm{F}=$ far; $N E=$ near; $N A=$ nature); $U, C M$ and $C R$ refer to the treatment $(\mathrm{U}=$ unmanaged; $C M$ = selective harvesting by management; $C R=$ selective harvesting by research). $A$ is an "attractor" plot, which represents a guiding model for management. $\mathrm{Md}=$ mixed deciduous; $\mathrm{P} / \mathrm{A}=$ Picea/Abies; Pin/Ab = Pinus/Abies; BE = Broadleaved Evergreen.

resource in Mexico. These forests are rich in biodiversity with at least 27 coniferous tree species, among them 20 species of Pinus, and 43 species of Quercus. The predominant forest types are mixed and uneven-aged pine-oak forests, representing more than two-thirds of the total area. The forests of Durango have been managed by local communities for more than 70 years, mainly using selective harvesting, for sustainable timber production but also for the maintenance of biological diversity and uneven-aged stand structures. Such selective forest management requires regular monitoring, and a new network of observational studies has been established. The network comprises 429 field plots, covering 0.25-ha each, that were established between 2007 and 2011, on the Sierra Madre Occidental (Figure 2).
Table 2 summarizes the stand variables calculated from the tree data assessed in the observational studies. The maximum and minimum values of the stand variables indicate that the network adequately represents the stand variability of mixed and uneven-aged forests of Durango. For example, the density of the sites ranges from 3.11 to 43.30 basal area per hectare. Such a wide amplitude of densities will make it possible to identify ideal residual (retention) basal areas to promote better rates of biomass accumulation.

The results of forest spatial analyses show that most tree species exhibit a high degree of spatial mingling; that the spatial distribution of small and large trees is clustered; and that horizontal and vertical forest structures are very irregular. Observed spatial tree mark associations seem to 


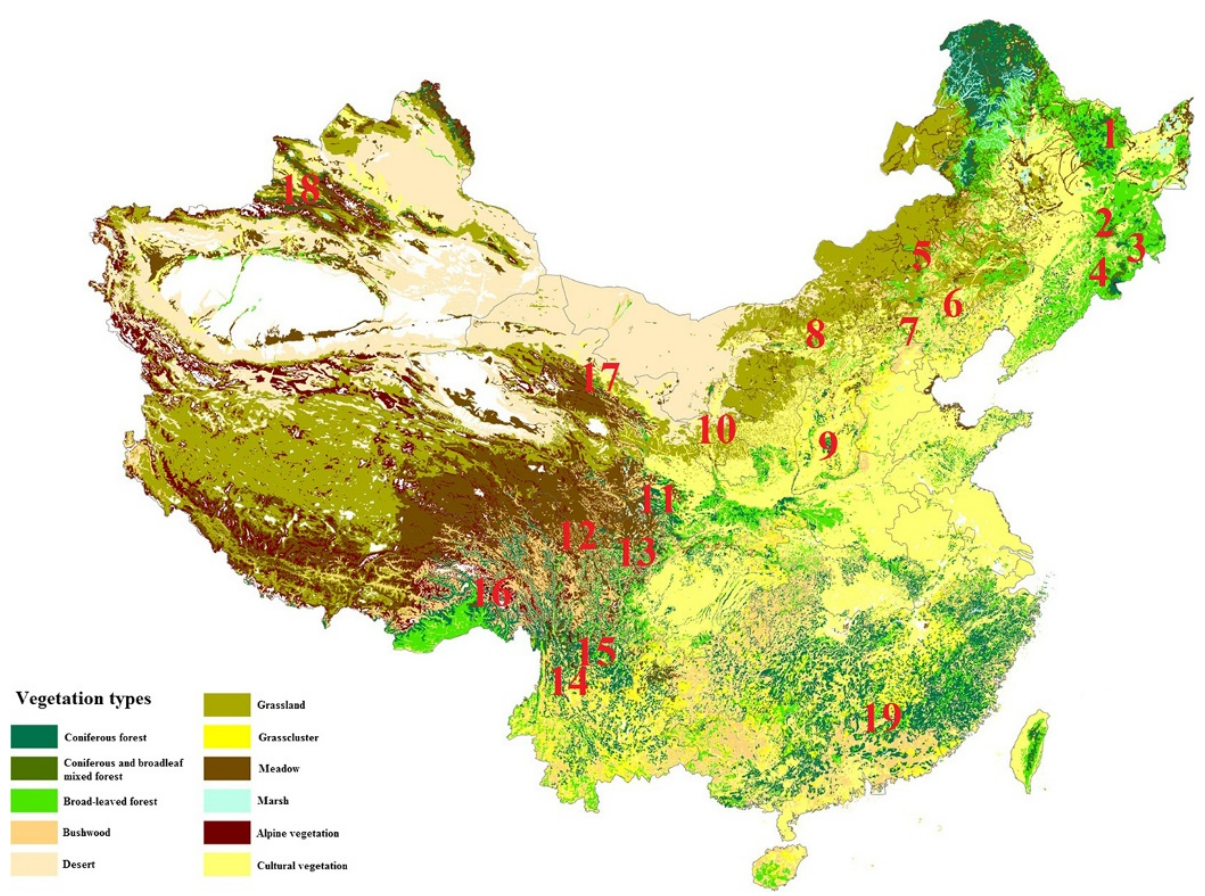

Figure 1 Geographical distribution of field plots and plot clusters in the Beijing forest ecosystems network.

be highly linked with seed dissemination processes, the relative shade tolerance of some tree species, and specific preferences for particular soil types. On the other hand, repulsive interactions could be an indication of competition processes that impose minimum distances between marks of trees. Selective tree removal is a major cause of spatial structuring (Longuetaud et al. 2008). For this reason, balanced structure areas are defined as the minimum contiguous area that is required for sustainable management of a multi-sized selection forest (Wehenkel et al. 2011). Such minimum areas which exhibit a balanced diameter distribution, and the corresponding number of trees, for different tree species and forest types are estimated based on data obtained from the new observational network.

Maintenance and extension of this forest observational network is currently secured for the next 6 years. The first 93 sites were re-measured during the winter of 2012. Mexico's National Forestry Commission recently approved the funding of 870 new observational study sites in Durango and an additional 3000 sites in other Mexican States. This network has thus already developed into a "green" infrastructure of national importance.

\section{Discussion and conclusions}

In this section, we show how forest observational studies may become part of a country's infrastructure. We also summarize the potential of long term field studies for analysing and modeling forest ecosystems in the context of interdisciplinary research. Finally, we discuss potential synergies between Forest Observational Studies and other Data Sources.

\section{Forest observational studies - ideal platform for interdisciplinary research}

An important longterm objective of many forest observational studies is to attract scholars from a variety of disciplines to provide holistic and hierarchically structured information about natural systems (including planted forests), and to exploit the potential for interdisciplinary research. Interdisciplinary research attempts to integrate methods, concepts and data from two or more disciplines (Ausburg 2006). Such efforts may advance fundamental understanding or help to solve problems whose solutions are beyond the scope of a single discipline. According to Kafatos and Eisner (2004), many of the great research triumphs are products of interdisciplinary inquiry and collaboration, including the discovery of the structure of DNA, magnetic resonance imaging, and human genome sequencing.

There are numerous examples of large scale ecosystem field studies which have been designed for interdisciplinary inquiry. Monserud (2002) describes seven silvicultural studies in the moist-maritime coastal regions of the Pacific Northwest: the Alternatives to Clearcutting study in Alaska; the Montane Alternative Silvicultural Systems 


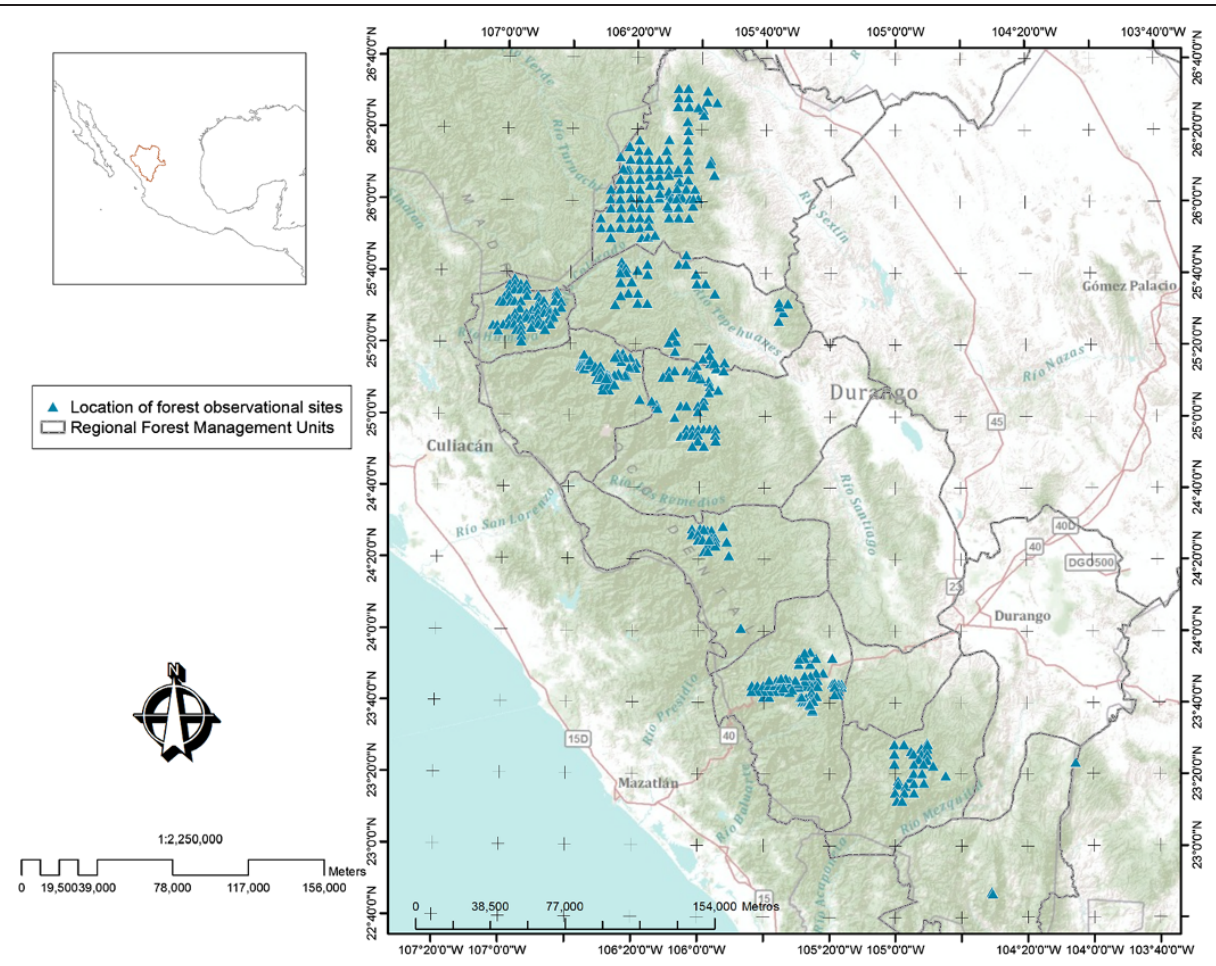

Figure 2 Location of the permanent forest observational sites in the pine-oak forests of Durango and some statistics of the $429(50 \times 50 \mathrm{~m})$ fiel plots of the Durango observational of the $429(50 \times 50 \mathrm{~m})$ fiel plots of the Durango observational network. The number of tree species recorded within the plots vary from 1 to 13 (average 7).

in British Columbia; the Olympic Habitat Development Study, the Forest Ecosystem Study and the Washington DNR Capitol Forest Study in Washington; the Demonstration of Ecosystem Management study in Washington and Oregon and the Density Management Study in Oregon. These seven interdisciplinary field studies are characterized by large spatial units with replicated treatments and multiple objectives (Szaro et al. 2006). The maintenance of such large experiments tends to be rather expensive, however, which may shorten their lifespan due to lack of funding, and thus restrict the essential continuity required in forest observational studies. Nevertheless, these studies have shown that field experiments provide an ideal platform for interdisciplinary investigation.
Using synergies between forest observational studies and other data sources

Data from observational experiments collected over long time periods may effectively complement forest inventories. New longterm observational networks with large plot areas and mapped tree data in America, Asia and Europe offer improved opportunities for detailed analysis, especially in uneven-aged, species-rich forests. Growth models are usually developed using data from long term FOS, but the spatial representation is often restricted. In order to test the applicability of the particular growth model for other regions, these models may be calibrated with data from forest inventories.

Table 2 Summary of selected stand variables of the Durango Observational Network: trees per hectare ( $\mathrm{N}$ ), stand basal area $\left(G, \mathrm{~m}^{2} \mathbf{h a}^{-1}\right)$, quadratic mean diameter $(\mathrm{dg}, \mathrm{cm})$, mean breast height diameter $(\mathrm{d}, \mathrm{cm})$, mean total height $(\mathrm{h}, \mathrm{m})$, dominant height $\left(\mathrm{H}_{0}, \mathrm{~m}\right)$, and dominant diameter $\left(\mathrm{D}_{0}, \mathrm{~cm}\right)$

\begin{tabular}{llllllll}
\hline Stand variable & $\boldsymbol{N}(\mathbf{N} / \mathbf{h a})$ & $\mathbf{G}\left(\boldsymbol{m}^{\mathbf{2}} \mathbf{h a}\right)$ & $\boldsymbol{D g}(\mathbf{c m})$ & $\boldsymbol{d}(\mathbf{c m})$ & $\boldsymbol{h}(\boldsymbol{m})$ & $\boldsymbol{H}_{\boldsymbol{o}}(\boldsymbol{m})$ & $\boldsymbol{D}_{\boldsymbol{o}}(\mathbf{c m})$ \\
\hline Mean & 661.98 & 19.99 & 20.46 & 18.00 & 11.09 & 18.97 & 56.04 \\
Maximum & 1600.00 & 43.28 & 45.46 & 42.31 & 23.21 & 36.60 & 95.10 \\
Minimum & 64.00 & 3.13 & 12.35 & 11.23 & 5.03 & 5.40 & 15.86 \\
Standard deviation & 324.46 & 7.96 & 4.84 & 4.49 & 3.35 & 6.98 & 16.38 \\
\hline
\end{tabular}

The last two variables were calculated as the top height and mean of the 100 largest diameter trees per hectare. 
Pelz and Kohnle (2012) cite (Lessard and Van Deusen Paul 2001) who states that growth models may be used to update information on inventory plots not visited in a particular year and that in turn, diameter growth models may be calibrated with inventory data by means of residual analysis. A similar calibration approach was reported by Nothdurft and Schmidt (2010). (de Menezes et al. 2000) list several methods for combining FOS and inventory data sets.

\section{Questions of scale}

Regarding spatial scale, (Seymour et al. 2006b) found that large-scale studies are difficult and expensive to install, replicate, monitor, and maintain over time. But there are also important benefits. Scientists learn to appreciate operational realities of forest management, and study sites provide realistic demonstrations of new silvicultural systems. Plot installations offer field laboratories where a wide range of questions can be addressed, including small-scale phenomena, such as amphibian dispersal and seedling development and whole-stand responses to silvicultural treatment. Large study areas are essential for developing species-area relationships (Hubbell 2001) where the effect of increasing areas on the number of species can be studied on the same site (Gadow and Hui 2007). Studies of competition effects at different spatial scales, species' habitat preferences (Zhang et al. 2009b) and analyses of sexual dimorphism in a dioecious tree species with widely scattered individuals (Zhang et al. 2012) also require large field plots.

Long-term studies are required for assessing the maximum density of a forest ecosystem. A classic example is provided by the South African "Correlated Curve Trend" (CCT) studies. The CCT studies were established with a wide range of extremely low and high densities. Some plots have been observed for more than 70 years providing unique information about tree survival in response to different initial spacings (Dickel et al. 2010). Trees are long-living organisms which react differently to changing environmental conditions during different life stages and long-term studies are required to assess these reactions.

It is not possible to capture all ecosystem phenomena and to apply all treatments of interest to a single network of permanent plots. Consequently, data from a variety of installations are often used in combination to develop comprehensive modeling frameworks (Amateis and Burkhart 2012). Thus forest modeling often helps to identify knowledge gaps, and to integrate and synthesize information from a variety of sources, to provide sound forecasting capability.

\section{New technical and methodological advances}

Three dimensional terrestrial laser scanning (TLS) and airborne laser scanning (ALS) possibly represent the most important technical advances in measurement and monitoring techniques relevant to forest observational studies. Ground-based TLS is used to measure objects in three dimensional space by emitting a laser beam and scanning the surface of surrounding objects using impulse or phasebased systems (Seidel 2014). Terrestrial laser scanning provides data about tree position, height, diameter at breast height, crown dimension, as well as tree lean, sweep and taper. However, suitable software for analysing the huge amounts of raw data does not seem to be freely available yet. ALS is based on similar technical principles, but the scanner is usually mounted on a small aircraft or helicopter. Possibly the first comprehensive textbook about forest applications of airborne laser scanning is the work by Maltamo et al. (2014) which provides a comprehensive, state-of-the-art review of the research and application of ALS in a broad range of forest-related disciplines. Some chapters deal with methodological detail while others review and illustrate the use of ALS within various domains of application to forest ecosystems.

New methods of analysing forest ecosystem structure and dynamics are being developed continuously. Examples include the ability to partition temperate plant community structure at different scales, to analyse spatial distributions and spatial associations of dominant tree species (Zhang et al. 2009a; Zhang et al. 2010b) and to describe genderrelated distributions, competition and habitat effects in old-growth forests (Zhang et al. 2009b; Zhang et al. 2010a). These methods are particularly useful and revealing if plot sizes are large to allow analysing the effects of scale.

More recent examples of analysing and modeling forest ecosystem dynamics are also based on observational field studies. Using large observational study in Northeast China, Temesgen et al. (2014) used a nonlinear mixed effect model with species indicators to make tree height predictions compatible and precise for 23 tree species found in multilayered forests in NE China. Corral-Rivas et al. developed generalized Height-Diameter Models with Random Parameters for Mixed, uneven- aged Forests in North-Western Durango, Mexico. Such models are important for estimating forest biomass. Laiho et al. (2014) estimate the height increment of understorey trees under different canopies while Valkonen et al. (2014) estimate ingrowth and survival of those trees. Both studies provide essential input for evaluating forest treatment options (Pukkala 2014; Vanclay 2014). Such modeling is only possible with appropriate measurements, collected in observational studies, sometimes over extended time periods.

\section{Timing assessments to analyse disturbances}

Models of tree growth, recruitment and survival represent the overwhelming result of traditional observational studies. But these models only describe a part of ecosystem 
dynamics. Equally important are the modifications caused by regular human disturbance in the form of clearfellings, plantings or tree harvesting. There is an abundance of tree growth models. In contrast, harvest event models predicting structural modifications based on silvicultural terminology, are virtually unknown. Yet such models are indispensable for comparing silvicultural alternatives in uneven-aged forests. To develop such a model requires harvest event data from observational studies where assessments are timed to coincide with the removals. A harvest event model should include estimates of the reduction of density (in terms of certain tree classes) and structural modifications (Mason et al. 2005). There is thus increasing motivation for analysing harvest events and using such data for modeling human disturbance.

\section{Forest observational studies - an essential part of a country's infrastructure}

The sustainable development of a country's forest ecosystems is the result of planned designs guided by a wide array of interests. Because they provide many essential services, forest ecosystems are generally considered a very important national asset. Data from observational experiments collected over long time periods may effectively complement forest inventory and monitoring. Growth models developed from observational studies are essential for projecting inventory data and for generating reasonable scenarios at landscape level. Long-term forest observational studies are therefore an essential part of a country's infrastructure, comparable to public transportation systems and energy supply services. Long term commitment and regular monitoring is required to ensure that forest resources are being sustained. Such commitment can only be guaranteed by the State.

An example of such a national infrastructure is given by Pelz and Kohnle (2012) who showed that at the end of the $19^{\text {th }}$ century, forest research stations were established in Prussia, Baden, Saxony, Württemberg and Hesse with the objective of long term observation of selected forest types. In 1872, a formal cooperation among these research stations was established by the Association of forest research stations in Germany (a founding member of the International Union of Forest Research Organizations, IUFRO). Several of the observational plots that were initiated in the $19^{\text {th }}$ century are still being re-measured today. The regular re-measurement, even during the war years, has produced an extensive and unique set of observations which provide the basis for detailed models of forest dynamics for different silvicultural treatments, and a variety of climatic and site effects. This achievement would not have been possible without the commitment of the State to create and continuously support such an extensive "green infrastructure". This infrastructure, staffed with permanently employed measurement teams, delivers essential information for monitoring national conservation efforts and develop climate adaptation strategies.

\section{Competing interests}

The authors declare that they have no competing interests.

\section{Authors' contributions}

All authors read and approved the final manuscript.

\section{Acknowledgement}

We greatly appreciate the constructive comments received from three anonymous reviewers which resulted in an extensive revision of the original submission. We thank the Forest Modeling Research Cooperative, and Harold Burkhart and Ralph Amateis at Virginia Tech, for providing material for this paper.

Individual author contributions: Zhao and Zhang (Section 2.2); Corral Rivas (Section 2.3); Temesgen (contributions to other sections): Gadow (Sections 1 and 3).

\section{Author details}

${ }^{1}$ Beijing Forestry University, Beijing, China. ${ }^{2}$ Universidad Autonóma de Nuevo León, Durango, México. ${ }^{3}$ Oregon State University, Corvallis, USA. ${ }^{4}$ Burckhardt Institute, Georg-August University, Göttingen, Germany. ${ }^{5}$ Institute of Forestry and Wood Science, University of Stellenbosch, Stellenbosch, South Africa.

Received: 30 December 2013 Accepted: 24 February 2014

Published: 11 April 2014

\section{References}

Amateis RL, Burkhart HE (2012) Rotation-age results from a loblolly pine spacing trial. South J Appl For 36:11-18

Ausburg T (2006) Becoming Interdisciplinary: An Introduction to Interdisciplinary Studies, 2nd edn. Kendall/Hunt Publishing, New York

Bosch J, Gadow K (1990) Regulating afforestation for water conservation in South Africa. S Afr For J No 153:41-54

Bungart R, Hüttl RF (2004) Growth dynamics and biomass accumulation of 8-year-old hybrid poplar clones in a short-rotation plantation on a clayey-sandy mining substrate with respect to plant nutrition and water budget. Eur J For Res 123(2):105-115

Burkhart HE (2008) Modelling growth and yield for intensively managed forests. J For Sci 24:119-126

Burkhart HE, Tomé M (2012) Modeling Forest Trees and Stands. Springer, p 457

Campbell D, Stanley J (1963) Experimental and Quasi-experimental Designs for Research and Teaching. In: Gage (ed) Handbook on Research on Teaching. Rand McNally, Chicago

Convention on Biological Diversity (2008) What is forest biological diversity? http://www.cbd.int/forest/what.shtml

Cook T, Campbell D (1979) Quasi-Experimental Design. Rand McNally, Chicago

Corral-Rivas JJ, Reyes RI, Wehenkel C, Aguirre-Calderón OA, Gadow K (2012) A Network of Forest Observational Studies in Durango (Mexico). Proceedings of an International Workshop at Beijing Forestry University, pp 125-138

Cox DR (1958) Planning of Experiments. Wiley, New York

Crawley MJ (2005) Statistics - An Introduction Using R. Wiley, p 327

De Barba M, Waits LP, Genovesi P, Randi E, Chirichella R, Cetto E (2010) Comparing opportunistic and systematic sampling methods for non-invasive genetic monitoring of a small translocated brown bear population. J Appl Ecol 47:172-181. doi:10.1111/j.1365-2664.2009.01752.x

de Menezes LM, Bunn DW, Taylor JW (2000) Review of guidelines for the use of combined forecasts. Eur J Oper Res 120:190-204

Dickel M, Kotze H, Gadow K, Zucchini W (2010) Growth and survival of eucalyptus grandis - a study based on modeling lifetime distributions. Intl J Math Comput For Nat Resour Sci 2(2):20-30, available online at HTTP://MCFNS.COM

Fisher RA (1935) The Design of Experiments, 1st edn. Oliver \& Boyd, London Gadow K, Kleinn C (2005) Forest Management, Science-Based and Understandable. In: Peterson CE, Maguire DA (eds) Balancing Ecosystem Values - Innovative Experiments for Sustainable Forestry. US Dept of Agr. Forest Service, Gen. Tech. Rep. PNW-GTR-635, pp 15-23

Gadow K, Hui GY (2007) Can the tree species-area relationship be derived from prior knowledge of the tree species richness? For Stud 46:13-22, 2007

Gao L, Zhang CY, Zhao XH, Gadow K (2010) Gender-related climate response of radial growth in dioecious fraxinus mandshurica trees. Tree-Ring Res 66(2):2010 
Hubbell SP (2001) The Unified Neutral Theory of Biogeography and Biodiversity. Princeton University Press, Princeton

Kafatos FC, Eisner T (2004) Unification in the century of biology. Science 303:1257 Kiviste A, Sims A, Laarmann D, Hordo M, Lilleleht A, Kangur A, Korjus H (2012) The Estonian Permanent Forest Plots Network. Proceedings of an International Workshop at Beijing Forestry University, pp 97-108

Kramer H (1988) Waldwachstumslehre. Verlag Paul Parey, Hamburg and Berlin, p 374 Kuehl RO (1994) Statistical Principles of Research Design and Analysis. Duxbury Press, Belmont, California, p 686

LaBau VJ, Bones JT, Kingsley NP, Lund HG, Smith WB (2007) A History of U.S. Department of Agriculture Forest Service Forest Survey, 1830-2004. In: McRoberts RE, Reams GA, Van Deusen PC, McWilliams WH (eds) Proceedings of the Seventh Annual Forest Inventory and Analysis Symposium; October 3-6, 2005; Portland, ME. Gen. Tech. Rep. WO-77. U.S. Department of Agriculture, Forest Service, Washington, DC, pp 9-10

Laiho O, Pukkala T, Lähde E (2014) Height increment of understorey Norway spruces under different tree canopies. For Ecosyst 1:4

Lee WK (1993) Wachstums- und Ertragsmodelle für Pinus Densiflora in der Kangwon-Provinz, Korea. Diss., Forstwiss. Cuvillier Verlag, Fachbereich, Univ. Göttingen, $\mathrm{p} 178 \mathrm{~S}$

Lessard VC, Van Deusen Paul C (2001) Updating Indiana Annual Forest Inventory and Analysis Plot Data Using Eastern Broadleaf Forest Diameter Growth Models. In: Reams Gregory A, McRoberts Ronald E (eds) Proceedings of the Second Annual Forest Inventory and Analysis Symposium; 2000 October 17-18; Salt Lake City, UT. Gen. Tech. Rep. SRS-47. U.S. Department of Agriculture, Forest Service, Southern Research Station, Asheville, NC, pp 66-69

Liu WG, Fan XH, Wang JS, Lu WM, Zhang CY, Gadow K (2011) The effect of 744 above- and belowground competition on the spectral reflectance of Fraxinus 745 mandshurica leaves. Int J Remote Sens, in print

Longuetaud F, Seifert T, Leban J-M, Pretzsch H (2008) Long-term dynamics of crowns in sessile oak stands by means of spatial analysis. For Ecol Manag 255:2007-2019

Maltamo M, Næsset E, Vauhkonen J (eds) (2014) Forestry Applications of Airborne Laser Scanning - Concepts and Case Studies, Springer Book Series Managing Forest Ecosystems, Vol. 27., p 412

Mason B, Kerr G, Pommerening A, Edwards C, Hale S, Ireland D, Moore R (2005) Continuous Cover Forestry in British Conifer Forests. In: Forest Research (2005). Annual report and accounts 2003-2004, pp 38-53

Ministerial Conference on the Protection of Forests in Europe (2008) Ministerial conference on the protection of forests in Europe. http://www.mcpfe.org/

Monserud RA (2002) Large-scale management experiments in the moist maritime forests of the Pacific Northwest. Landsc Urban Plan 59(3):159-180

Montréal Process (1998) Criteria and Indicators for the Conservation and Sustainable Management of Temperate and Boreal Forests. The Montreal Process, Montreal, http://www.rinya.maff.go.jp/mpci/

Nothdurft A, Schmidt M (2010) Kalibrierfähige Modelle für Simultane Prognosen von Durchmesser und Höhe bei Waldinventuren - Integrierte Nutzung von Langzeitbeobachtungen auf Versuchsflächen, DVFFA - Sektion Ertragskunde, Jahrestagung 2010., pp 125-130

O'Hehir J (2001) Growth and Yield Models for South Australian Radiata Pine Plantations Incorporating Fertilising and Thinning. PhD dissertation, Institute of Land and Food Resources, University of Melbourne, p 167

Pelz DR, Kohnle U (2012) Forest Observational Studies in Germany. In: Zhao XH, Zhang CY, Gadow K (eds) Forest Observational Studies. Proceedings of an International Workshop at Beijing Forestry University, pp 109-124

Pretzsch H (2009) Forest Dynamics, Growth and Yield. Springer, p 684

Pukkala T (2014) Stand management optimization - the role of simplifications, For Ecosyst 1:3

Radtke PJ, Amateis RL, Prisley SP, Copenheaver CA, Chojnacky DC, Püttman JR, Burkhart HE (2009) Modeling production and decay of coarse woody debris in loblolly pine plantations. For Ecol Manage 257:790-799

Seidel D (2014) 3D-Terrestrial laser scanning. http://wiki.awfforst.uni-goettingen.de/ wiki /indexphp/ 3D- Terrestrial_laser scanning (date read: 3rd February, 2014)

Seymour RS, Guldin J, Marshall DM, Palik B (2006a) Large-scale, long-term silvicultural experiments in the United States: historical overview and contemporary examples. Allg Forst u J Ztg 177(6/7):104-112

Seymour RS, Guldin J, Marshall D, Palik B (2006b) Large-scale, long-term silvicultural experiments in the United States: historical overview and contemporary examples. Allg Forst u J Ztg 177(6/7):104-112
Sims A, Kangur A, Hordo M, Kiviste A, Jögiste K, Gadow K (2009) Tracking disturbance-induced changes in stand development at irregular measurement intervals in the järvselja forest experiments. Balt For 15(2):151-160

Spellmann H, Wagner S, Nagel J, Guericke M, Griese F (1996) In der Tradition stehend, neue Wege beschreitend. Forst u Holz 51(11):363-368

Szaro RC, Peterson CE, Gadow K (2006) Operational experiments for sustainably managing forests. Allg Forst u J Ztg 177(6/7):98-104

Temesgen H, Zhang C, Zhao X (2014) Modelling tree height-diameter relationships of multi-species and multi-layered forests: a large observational study from Northeast China. For Ecol Manag 276:139-145

Tewari VP, Sukumar R, Kumar R, Gadow K (2014) Forest observational studies in India - past developments and future prospects. For Ecol Manage Spec Issue For Observational Stud, in press

Tomppo E, Gschwantner T, Lawrence M, McRoberts RE (eds) (2010) National Forest Inventories - Pathways for Common Reporting, vol XXVI, Springer Book Series Managing Forest Ecosystems., p 612

Valkonen S, Eerikäinen K, Saksa T (2014) Ingrowth, survival and height growth of small trees in uneven-aged Picea abies stands in southern Finland. For Ecosyst 1:5

Vanclay JK (1994) Modelling Forest Growth - Applications to Mixed Tropical Forests. CAB International, Wallingford, UK

Vanclay JK (2014) Unsuspected implications arising from assumptions in simulations: Insights from recasting a forest growth model in system dynamics. For Ecosyst 1:7

Wang J, Zhang C, Xia F, Zhao X, Wu L, Gadow K (2011) Biomass structure and allometry of Abies nephrolepis (Maxim) in Northeast China. Silva Fennica 45(2):211-226

Wehenkel C, Corral-Rivas JJ, Hernández-Díaz JC, Gadow K (2011) Estimating balanced structure areas in multi-species forests on the Sierra Madre Occidental, Mexico. Ann For Sci 68:385-394

Zhang CY, Zhao XH, Liu XD, Gadow K (2009a) Spatial distributions and spatial associations of dominant tree species in Korean pine broadleaved oldgrowth forests in Changbai Mountains. Balt For 16(1):66-74

Zhang CY, Zhao XH, Gadow K (2009b) Gender, neighboring competition and habitat effects on the stem growth of dioecious Fraxinus mandshurica trees in a northern temperate forest. Ann For Sci 66:812-821

Zhang CY, Zhao XH, Zhang CY, Zhao XH, Gao L, Gadow K (2010a) Gender-related distributions of Fraxinus mandshurica in secondary and old-growth forests. Acta Oecol 36:55-62

Zhang CY, Zhao XH, Gadow K (2010b) Partitioning temperate plant community structure at different scales. Acta Oecol 36:306-313

Zhang CY, Wang J, Zhao XH, Xia FC, Gadow K (2012) Sexual dimorphism in reproductive and vegetative allometry for two dioecious Rhamnus plants in north-eastern China. Eur J For Res 131:1287-1296

Zhao XH, Zhang CY, Gadow K (2011) Forest Observational Networks. Proceedings of the IUFRO-EFI-ICFFI Conference "Ecosystem Design for Multiple Serviceswith an Emphasis on Eurasian Boreal Forests". St. Petersburg Forest Technical University, St. Petersburg/Russia, pp 34-47, 9-11 November, 2011

Zhao XH, Zhang CY, Gadow K (2012) A Forest Observational Network for China. Proceedings of an International Workshop at Beijing Forestry University, pp 1-16

doi:10.1186/2197-5620-1-8

Cite this article as: Zhao et al:: Forest observational studies-an essential infrastructure for sustainable use of natural resources. Forest Ecosystems 2014 1:8.

\section{Submit your manuscript to a SpringerOpen ${ }^{\odot}$ journal and benefit from:}

- Convenient online submission

- Rigorous peer review

- Immediate publication on acceptance

- Open access: articles freely available online

- High visibility within the field

- Retaining the copyright to your article

Submit your next manuscript at $>$ springeropen.com 